\title{
O ESTADO NA DEMOCRACIA DELIBERATIVA: AS RAÍZES DE UMA ANTINOMIA
}

\author{
Francisco Mata Machado \\ Universidade Federal de Goiás -UFG, Goiânia, GO - Brasil. <franciscotavares@ufg.br> \\ http://dx.doi.org/10.1590/ 0102-6445225-257/95
}

Ao englobar a noção de soberania popular, a teoria democrática moderna acompanha um incessante debate desde sua mais remota gênese. A crítica ao confinamento eleitoral do princípio democrático é, nesse contexto, um tema recorrente. $\mathrm{O}$ argumento vem desde Rousseau (2002, p. 45) e o seu enunciado de que o povo inglês só seria livre "durante a eleição dos membros do Parlamento". Posteriormente, o jovem Marx (2005, p. 135) defende um processo de "eleição ilimitada" que, sugeriu, levaria o Estado à própria dissolução. Na contemporaneidade, assume a forma de práticas como a participação social em espaços decisórios, a instauração de novos mecanismos de accountability vertical, ou a garantia de que os cidadãos possam influenciar os governos por meio do tirocínio público e da informalidade de suas opiniões. O conjunto de correntes do pensamento democrático que propõe uma ampliação tanto dos meios formais como dos informais para o exercício da soberania popular se abriga sob o amplo conceito de democracia radical.

Sob um ângulo teórico, o cerne da democracia radical em acepção contemporânea são a crítica e a formulação de 
alternativas rivais às concepções políticas do liberalismo, para as quais parte da literatura atribui o genérico nome de "democracia hegemônica" (cf. Santos e Avritzer, 2002), conceito em cujo amplo espectro semântico se incluem desde variantes do elitismo até o pensamento democrático-pluralista ${ }^{1}$. O ideário democrático-radical dos dias atuais não é, todavia, uniforme ou estável em suas distintas variantes. Assim, correntes como o republicanismo de linhagem rousseauniana, a democracia como cooperação reflexiva extraída do pragmatismo de Dewey e recepcionada por Honneth, o agonismo democrático proposto por Mouffe e o procedimentalismo deliberacionista de gênese habermasiana exemplificam troncos da democracia radical, os quais acompanham os estudos políticos ao menos desde os últimos lustros do século $\mathrm{XX}^{2}$. Este artigo tem como objeto teórico a versão deliberativa da democracia radical contemporânea.

O modelo normativo da democracia deliberativa é 226 expressão de uma corrente de pensamento que se ancora na premissa, inspirada pelo pensamento pragmatista e pela teoria do discurso, segundo a qual "o nível discursivo do debate público constitui a variável mais importante" (Habermas, 1997, v. II, p. 28) para os processos de produção e de legitimação de normas e políticas.

A espécie de democracia radical expressada no procedimentalismo democrático deliberacionista se situa, em

\footnotetext{
1 Habermas (1997, v. II, p. 59) é um dos autores que tenta, quanto aos fundamentos e premissas normativas, focar-se nas semelhanças entre o chamado elitismo democrático e o pluralismo: "A teoria social do pluralismo insere-se no modelo normativo do liberalismo através de uma simples substituição: o lugar dos cidadãos e de seus interesses individuais é ocupado por organizações e interesses organizados".

2 Um mapeamento dos principais pressupostos da democracia radical republicana, deliberativa e cooperativo-reflexiva, seguido de uma defesa desta, é exposto em Honneth (2001, pp. 63-91). Uma comparação entre o deliberacionismo e o participativismo republicano como espécies do gênero "democracia radical" se encontra em Cohen e Fung (2004). O modelo agonístico de democracia é apresentado, sob a forma de uma contraposição à democracia deliberativa, em Mouffe (2000).
} 
relação às principais (e rivais) compreensões democráticas contemporâneas, como uma teoria da democracia que se pretende equidistante entre o republicanismo e o liberalismo. Como aquele, alberga-se sob a tese do déficit de legitimidade acarretado pelos limitados canais de influência ou participação franqueados na democracia liberal e, como este, advoga a imprescindibilidade de um tipo específico de constitucionalismo, assegurador da autonomia privada.

A democracia deliberativa, como proposta de síntese que visa superar o liberalismo e o republicanismo, comparece aos debates sobre os problemas fundamentais da filosofia política contemporânea e se pronuncia genuinamente quanto a temáticas como o fundamento de legitimidade do Estado e do direito; o tratamento da tensão entre autonomia pública e autonomia privada (e, por conseguinte, entre soberania popular e direitos humanos); a relação entre procedimento e substância na conformação das instituições e dos respectivos processos decisórios; e a definição da democracia de nossos dias como método autorizativo de elites governantes ou como participação efetiva dos cidadãos na produção de normas e políticas, entre outras.

É extensa a literatura acerca dos fundamentos, das aplicações e da plausibilidade da democracia deliberativa, como igualmente vasta é a discussão concernente às distintas e, frequentemente, antagônicas variantes do modelo de democracia em questão. À medida que a dimensão discursiva e comunicacional da política ganha terreno sobre os estudos e experimentos institucionais ${ }^{3}$, mais amplo se torna o espectro de proposições e de argumentos a se identificarem com a democracia deliberativa, de maneira que múltiplas concepções quanto aos processos decisórios públicos e à legitimidade das decisões se filiam expressamente ao campo teórico em questão.

3 Bohman (1998) notou a chegada de uma autêntica "era" da democracia deliberativa. 
Decorridos mais de vinte anos desde a publicação dos trabalhos que delimitaram a corrente de pensamento e as orientações normativas da democracia deliberativa ${ }^{4}$, identifica-se um rol de problemas filosófico-políticos e analítico-empíricos que permanecem a desafiar estudiosos e agentes públicos associados a proposições ou práticas deliberacionistas. Assuntos como o papel do agir estratégico na deliberação (Mansbridge et al., 2009), a aferição empírica do ideal normativo deliberacionista (Steenbergen et al., 2003) e a plausibilidade de processos deliberativos em amplas escalas (Dryzek, 2004) exemplificam a extensa lista de temas que despertam a curiosidade e animam as controvérsias científicas e teóricas nesse campo de estudos. Dentre esses problemas, há um debate especialmente interessante e recorrente, cujo itinerário pode ser traçado desde os primeiros momentos dessa teoria até os dias atuais. Trata-se da definição do papel reser228 vado ao Estado e ao seu aparato, para que sejam alcançados os propósitos normativos de uma deliberação ideal. Este é o objeto deste artigo.

$\mathrm{O}$ primeiro objetivo aqui perseguido reside em uma apresentação do solo filosófico em que se edifica a teoria da democracia deliberativa. Em seguida, resgata-se, a partir das primeiras controvérsias entre os pioneiros dessa corrente, Habermas e Cohen, a origem dos diferentes papéis esperados do Estado na deliberação pública. Essas duas tarefas pretendem pavimentar o terreno argumentativo para a fundamentação do entendimento, cerne deste artigo, segundo o qual as ambiguidades e omissões próprias ao tratamento conferido pela democracia deliberativa ao Estado e suas instituições têm uma origem e

\footnotetext{
4 Dois textos representativos da primeira delimitação da corrente teórica em questão, bem como das divergências que, atualmente, se projetam na multiplicidade de compreensões acerca dos pressupostos, do conteúdo e dos propósitos da deliberação pública, se encontram em Cohen (1989) e Habermas (1997, v. II).
} 
explicação mais profunda. Revelam, de fato, o ponto mais nitidamente visível de uma estrutura filosófica que já carrega ambivalências e imprecisões em seus mais elementares fundamentos.

Inicialmente, procede-se a uma apresentação sucinta do marco filosófico habermasiano, principal arcabouço da democracia deliberativa. Por meio dessa exposição, pretende-se mostrar o modo como Habermas compreende o Estado no conjunto de sua obra, erigida ao redor de uma teoria da ação e da racionalidade que procurou irromper para além dos limites do agir racional entendido como adequação entre meios eleitos e finalidades predeterminadas.

Em seguida, discute-se o específico tipo de procedimentalismo democrático associado à corrente deliberacionista, bem como os distintos - e rivais - posicionamentos adotados quanto ao assunto por dois autores pioneiros nesse campo teórico: Jürgen Habermas e Joshua Cohen.

Depois é abordado diretamente o problema do papel reservado ao Estado na democracia deliberativa, apresentando-se a controvérsia entre o entendimento de que a burocracia deve ser estritamente porosa à influência dos fluxos comunicativos provenientes da esfera pública e, em contraposição, a tese de que o Estado deve promover e organizar a deliberação em fóruns inseridos no respectivo aparato. Espera-se indicar que essa controvérsia não é incidental ou menor no âmbito da teoria da democracia deliberativa. Ao contrário, as contraditórias ou, quando menos, antitéticas apreensões sobre o papel do Estado na deliberação pública, identificadas entre os variados autores que se afiliam a esse campo, podem ser percebidas como frutos de tensões ou mesmo contradições presentes ainda nos fundamentos filosóficos dessa influente corrente do pensamento político de nossos dias. 


\section{A influência habermasiana sobre a relação entre Estado e deliberação pública no modelo normativo da democracia deliberativa}

É suficientemente aceita no âmbito da teoria democrática contemporânea a premissa de que o trabalho filosófico-político de Jürgen Habermas se define como a principal influência e o mais relevante discurso de justificação da concepção deliberacionista de democracia, ao menos em suas primeiras formulações (Bächtiger et al., 2009) ${ }^{5}$. Desse modo, um estudo sobre eventuais tensões ou antinomias no âmbito dessa corrente teórica, como este, deve partir dessa base ou gênese que lhe informa e conforma.

Primeiramente, é preciso conhecer a taxonomia habermasiana quanto aos modelos de ação social e suas características principais. Segundo o autor, o agir pode ser entendido de acordo com as seguintes variantes: agir teleológico (do qual o agir estratégico é um caso ampliado), agir regulado 230 por normas, agir dramatúrgico e agir comunicativo.

No modelo teleológico de ação, um agente, concebido individualmente, propõe-se a alterar algo em sua realidade externa-objetiva com vistas à obtenção de alguma finalidade que lhe é desejada de modo predeterminado. O critério de racionalidade a controlar essa ação humana é a eficiência, ou seja, a capacidade de se alcançar um proveito ou interesse de saída pretendido. Quando se trata da direta atuação sobre o meio, uma racionalidade cognitivo-instrumental tem lugar. Quando é o caso de se considerar, como em um jogo, as escolhas e alternativas que serão efetivadas por outros agentes, fala-se em uma racionalidade estratégica.

\footnotetext{
5 O citado artigo, ao dispor sobre duas fases ou tipos de democracia deliberativa, a primeira habermasiana e a segunda extra-habermasiana, propõe como representante desta última variante ninguém menos do que Jürgen Habermas em seus escritos atuais, os quais, como se sabe, não encerram grandes retificações ou renúncias ao esquema filosófico mais amplo do autor. Ou seja, o caráter habermasiano da democracia deliberativa parece suficientemente incontroverso.
} 
$\mathrm{O}$ agir regulado por normas pressupõe, além de um mundo objetivo, um mundo social. Aqui, portanto, mais do que os juízos de verdade proposicional e de eficiência entre meios e fins atinentes ao modelo de ação acima apresentado, é a validade (aceitação mútua e justificada) das normas pelos agentes potencialmente atingidos por seu conteúdo o juízo norteador da ação social. Em complementação a um "complexo cognitivo", como no agir teleológico, exige-se dos atores um "complexo motivacional" a lhes permitir reconhecer como válidas determinadas práticas em relação aos outros seres humanos com os quais o agente se enreda socialmente (Habermas, 2012).

No agir dramatúrgico, antes do mundo externo objetivo (agir teleológico), ou do mundo intersubjetivo social (agir regulado por normas), é o mundo "interno" dos agentes que recebe ênfase e a maneira como elementos desse universo são filtrados e levados à experiência social é que dá o tom desse modelo de ação. Assim, diferentemente da eficiência e da validade, é a sinceridade o critério primaz da racionalidade do agir dramatúrgico (Habermas, 2012).

$\mathrm{O}$ agir comunicativo - modelo de ação que Habermas vai desenvolver a partir de uma tripla influência do interacionismo simbólico de Mead, da teoria dos jogos de linguagem do segundo Wittgenstein e da hermenêutica de Gadamer - conta com um grau de reflexividade ausente nos demais modelos de ação e pressupõe uma tripla referência ao mundo, como mundo objetivo, social e subjetivo. Por meio do uso da linguagem, atores intercambiam posições e pretensões de validade, orientados à obtenção de um entendimento, que será alcançado de modo cooperativo e com o emprego das três noções de racionalidade anteriormente mencionadas, em grau de mútua articulação (Habermas, 2012).

A racionalidade reflexiva e obtida por uma prática social que é a um só tempo processo (retórica), procedi- 
mento regulamentado por normas (dialética) e um produto observável (lógica), tal como ocorrente na argumentação, é conformadora do agir comunicativo, que tem lugar histórico somente na modernidade, quando estão dadas as condições de racionalização social e de reflexividade adequadas (Habermas, 2012).

A partir dessa resumida apresentação, é possível afirmar que a democracia deliberativa e seu originário ideal normativo se definiram como um discurso de aplicação, repleto de nuances, da ideia de racionalidade comunicativa para o campo da política. Assim, um caminho intuitivo ou apressado poderia levar à conclusão de que a política deliberativa condiz com a promoção de um ambiente em que sujeitos que se reconhecem como livres, iguais e racionais intercambiam razões validadas pela verdade proposicional, pela adequação normativa e pela sinceridade dos agentes, de modo a alcançarem um entendimento racionalmente 232 informado. Apenas com esses dados, seria possível sugerir que o papel do Estado na deliberação pública consistiria em promover, incentivar e fomentar instâncias decisórias afins à argumentação política condizente com o modelo de ação comunicativa que, antes de se orientar pelo êxito dos agentes, é voltado ao entendimento.

O problema, entretanto, é mais complexo do que essa hipótese indica, uma vez que, para a devida composição do substrato filosófico habermasiano, não é suficiente uma analítica exposição do conceito de agir comunicativo. É necessário, ao menos, contextualizar e delimitar o modelo de ação em questão segundo duas categorias indispensáveis à apreensão habermasiana da modernidade e imprescindíveis para a compreensão da política no trabalho do autor: sistemas sociais e mundo da vida.

A sociedade, em Habermas, pode ser entendida segundo uma dualidade, atinente à perspectiva do observador e à perspectiva do participante. Em relação a esta última, 
tem lugar uma categoria que congrega as práticas compatíveis com o modelo comunicativo de ação e que encerra um pano de fundo de valores, referências, conceitos e tradições comungados pelos agentes. Para essa categoria, Habermas toma o conceito de mundo da vida (Lebenswelt). Afirma o autor que o mundo da vida é composto por "paradigmas culturais, ordens legítimas e estruturas pessoais" (Habermas, 2002b, p. 138), que podem ser imaginados como "formas condensadas dos (e sedimentos depositados pelos) seguintes processos que operam através da ação comunicativa: entendimento, coordenação da ação e socialização" (Habermas, 2002b, p. 38, grifo no original). O mundo da vida e suas redes comunicativas permitem a reprodução e o desenvolvimento da cultura, da sociedade e das estruturas de personalidade. Na modernidade, entretanto, a reprodução de sociedades complexas não pode depender apenas dos processos interativos - comunicativos - ocorrentes no mundo da vida. Como afirma Habermas (2012, p. 142),

A tradição cultural [...] tem de interpretar o mundo da vida de maneira que o agir voltado ao êxito seja liberado dos imperativos de um entendimento que precise ser renovado por via comunicativa e possa ser desacoplado, ao menos parcialmente, do agir orientado para o entendimento. Com isso se tornará possível uma institucionalização social do agir racional-finalista em favor de propósitos generalizados: em favor, por exemplo, da formação de um subsistema monitorado com dinheiro e poder, para o gerenciamento econômico racional e para uma administração racional.

Coerentemente com essa constatação transcrita, tem-se que, para além da sociedade sob a perspectiva dos participantes (mundo da vida), Habermas considera a sociedade sob a perspectiva do observador, fazendo-o mediante o manejo do conceito parsoniano de sistemas regulativos, 
os quais são conduzidos por meios e devem ser aptos a reduzir, em termos funcionalmente eficientes, a complexidade social e suas inúmeras sucessões de expectativas e contingências.

A partir do léxico anteriormente sumarizado, é possível notar que, em Habermas, o conflito social moderno se dá entre sistema e mundo da vida. $\mathrm{O}$ risco de que a lógica daquele se insira nas redes informais e colonize a riqueza comunicacional deste é o grande desafio apresentado ao projeto emancipatório da modernidade tardia. Assim, a redução da experiência humana à linguagem dos preços com que opera o sistema da economia/mercado, ou à linguagem do poder administrativo própria ao Estado, representa uma ameaça à racionalidade comunicativa e, por consequência, ao exercício da autonomia (ou imputabilidade) entre os sujeitos livres, iguais e racionais que argumentam com vistas ao entendimento no mundo da vida.

234 A filosofia política habermasiana, consolidada no modelo normativo da democracia deliberativa, consiste da busca por uma prática política que refreie a colonização do mundo da vida pelos sistemas da economia e do Estado. A burocracia estatal é, portanto, ao menos a princípio, mais uma ameaça do que uma garantia ao modelo de ação condizente com o conceito de deliberação com que opera o modelo normativo da democracia deliberativa em sua formulação original.

Uma última categoria é relevante para essa exposição do pavimento filosófico sobre o qual se edifica a democracia deliberativa. Trata-se do conceito de esfera pública, com o qual Habermas operou desde a sua tese de livre-docência e que, em sua principal obra política, Direito e democracia: entre facticidade e validade, fora reabilitado para além da figura histórica própria ao século XIX que o autor estudara em 1962, e em relação à qual identificara uma decadência concorrente ao surgimento da sociedade de massas. Uma 
formulação sintética do conceito de esfera pública geral ${ }^{6}$ foi assim apresentada por Lubenow (2010, p. 236):

A esfera pública é uma "estrutura intermediária" que faz a mediação entre o Estado e o sistema político e os setores privados do mundo da vida. Uma "estrutura comunicativa", um centro potencial de comunicação pública, que revela um raciocínio de natureza pública, de formação da opinião e da vontade política, enraizada no mundo da vida através da sociedade civil. A esfera pública tem a ver com o "espaço social" do qual pode emergir uma formação discursiva da opinião e da vontade política. No seu bojo colidem os conflitos em torno do controle dos fluxos comunicativos que percorrem o limiar entre o mundo da vida e a sociedade civil e o sistema político e administrativo. A esfera pública constitui uma "caixa de ressonância", dotada de um sistema de sensores sensíveis ao âmbito de toda sociedade, e tem a função de filtrar e sintetizar temas, argumentos e contribuições, e transportá-los para o nível dos processos institucionalizados de resolução e decisão, de introduzir no sistema político os conflitos existentes na sociedade civil, a fim de exercer influência e direcionar os processos de regulação e circulação do poder do sistema político através de uma abertura estrutural, sensível e porosa, ancorada no mundo da vida.

6 Os limites temáticos deste artigo impedem uma abordagem crítica mais detida sobre a categoria esfera pública. Para uma refutação à associação habermasiana entre liberalismo oitocentista e origem da esfera pública, ver Burke (2002). Para uma leitura crítica das conclusões pretendidas por Habermas, com a ideia de esfera pública, por meio de um hipostasiamento de uma forma própria aos homens, burgueses e europeus na fase liberal do capitalismo, ver Gurza Lavalle (1997). Para a reposição do conceito de esfera pública pela ideia de "esfera pública operária”, ver Negt e Kluge (1993). E, enfim, para se conhecer as razões do próprio Habermas, em diálogo com inúmeros críticos, como Nancy Fraser e Agnes Heller, para insistir nesse conceito até a atualidade, ver o já clássico Habermas and the public sphere (Calhoun, 1992). 
A democracia deliberativa diz respeito a uma concepção política segundo a qual o sistema estatal deve se revelar poroso e influenciável pelos argumentos, temas e discursos de justificação engendrados em ações comunicativas ocorrentes na esfera pública, de modo que os fluxos comunicativos egressos do mundo da vida sejam capazes de legitimar a lógica sistêmica estatal que, assim, não se autonomiza ou se descola de modo hermético do mundo da vida ${ }^{7}$.

Para alcançar tais desígnios, Habermas entende como legítimas as decisões proferidas em conformidade com dois princípios que parecem explicitar, para o campo da política, o que se espera de práticas comunicativas: o princípio $d$ e o princípio $u$. Habermas formula o princípio $d$ (princípio do discurso) como aquele que entrega validade às normas de ação "que poderiam encontrar o assentimento de todos os potencialmente atingidos, na medida em que estes participam de discursos racionais" (Habermas, 2003, v. I, p. 164). 236 Já o princípio $u$ (princípio de universalização, ou de generalização) "obriga os participantes do discurso a examinar normas controversas, servindo-se de casos particulares previsivelmente típicos, para refletir se elas poderiam encontrar o assentimento refletido de todos os atingidos" (Habermas, 2003, v. I, p. 203).

Esses princípios foram objeto de contestação desde os primeiros aportes acadêmicos sobre a democracia deliberativa. Uma clivagem, em especial, é constitutiva dos inúmeros desmembramentos que o debate sobre Estado e democracia

\footnotetext{
7 A relação entre a esfera pública do mundo da vida e a lógica sistêmica da burocracia estatal sempre esteve presente na obra de Habermas. Para o autor, por um lado, reconhecendo-se um plano sistêmico à política, "não podemos excluir do conceito de político o elemento de ação estratégica" e "a violência sempre foi parte integrante dos meios para a aquisição e preservação do poder"; por outro lado, já antevendo os princípios $d$ e $u$, que orientam normativamente a prática deliberativa, afirma o autor que "o poder legítimo só se origina entre aqueles que formam convicções comuns em um processo de comunicação não coercitiva” (ver Habermas, 1980, pp. 115 e 117).
} 
deliberativa assumiu ao longo dos anos. Trata-se da distinção entre o modelo habermasiano de democracia deliberativa e a proposição apresentada por Joshua Cohen. Esta, inobstante influenciada por Habermas, procurou apontar críticas e contribuições alternativas, em especial no que se refere ao papel do Estado na deliberação pública. O debate que ressai dessas objeções será tratado a seguir e exposto a partir de um fio condutor localizado nas variações atinentes à relação entre procedimento e substância para a democracia deliberativa.

\section{A relação entre procedimento e substância na democracia deliberativa: 0 debate entre Habermas e Cohen}

A democracia deliberativa, em acordo com um amplo conjunto de vertentes, a alcançar de Schumpeter e Kelsen aos participativistas, guarda uma compreensão preponderantemente procedimental do princípio democrático ${ }^{8}$. De início, contudo, já é possível pontuar-se que a democracia deliberativa não é radicalmente e sem ressalvas político-procedimentalista, o que a distingue das concepções agregativas. A validade de normas e políticas não se ancora, para o deliberacionismo, na obtenção de maioria, ou mesmo de unanimidade, como condições suficientes. Não se trata de um procedimentalismo "puro", no contexto do qual qualquer decisão política colhe validade última e estrita no próprio processo

8 É, aliás, esse consenso quanto ao procedimentalismo democrático que explica, por exemplo, a possibilidade de se reconhecer processos transicionais e políticas substantivas muito diferentes entre si como igualmente democráticos. A transcrição a seguir, extraída de um texto de Rustow (1999, p. 22; tradução do autor) amplamente discutido, é indicativa desse argumento: "Especificamente, não há por que pressupor que a transição para a democracia seja um processo uniforme em escala mundial, que envolva as mesmas classes sociais, os mesmos tipos de questões políticas ou os mesmos métodos para a solucioná-las. Ao contrário, talvez seja como Harry Eckstein supõe: que uma ampla variedade de conflitos sociais e de confrontos políticos possa ser combinada com a democracia. Isto está, é claro, em consonância com o reconhecimento geral de que a democracia é uma matéria primariamente de procedimento antes que de substância." 
em que o critério agregativo da maioria indica o melhor caminho a seguir. Mesmo na formulação mais intensamente procedimentalista, sustentada por Habermas, não basta a composição de preferências em processos abertos a todos os interessados para se validar as decisões políticas.

A relação entre o conteúdo das decisões políticas e o processo decisório é oscilante também no interior da corrente teórica deliberacionista, conforme se pode concluir das versões de Habermas e Cohen, apresentadas a seguir.

\section{O procedimentalismo habermasiano: síntese pragmática entre direito e política ou circularidade?}

A teoria política estampada em Direito e democracia: entre facticidade e validade, e nos escritos políticos subsequentes de Jürgen Habermas, se situa, no que tange à fundamentação do direito e à sua relação com a política, como equidistante entre o positivismo e o naturalismo, de tal arte que não 238 endossa o relativismo moral típico da versão kelseniana daquele e, tampouco, o fundacionalismo, em geral metafísico, próprio das distintas manifestações deste.

A solução procedimentalista é parte fundamental da engenharia político-filosófica empreendida pelo autor para contornar os conhecidos problemas das linhas de pensamento antes referidas. Remeter a política e o direito aos processos discursivos em que são engendrados, antes de socorrer a explicações últimas naturalistas, ou de um ceticismo moral que tende a reificar as instituições postas, como faz o positivismo, é parte do empreendimento jurídico-filosófico e político-filosófico a que Habermas se propõe.

A chave explicativa da leitura procedimental atribuída por Habermas à política reside em sua identificação da mútua pressuposição e cooriginalidade entre as autonomias pública e privada. As políticas e normas, por um lado, colhem validade à exata medida em que são percebidas 
por sujeitos integrantes de uma comunidade jurídica na condição de fruto do seu acordo, das suas razões, do seu assentimento e dos discursos em que os participantes livres, iguais e racionais se engajam. Sem um reconhecimento da racionalidade intrínseca e da dignidade imanente desses sujeitos, o critério de validade aqui enunciado tornar-se-ia contraditório, uma vez que seres não autônomos ou ameaçados em sua integridade subjetiva não podem ter um sentimento recognitivo tão intenso como o de autoria de uma ordem jurídico-política. Se os cidadãos devem se ver como autores das normas e das decisões políticas, como corolário infere-se que lhes é reconhecida e, ademais, assegurada, a plenitude da autonomia privada, sem a qual não há base fática ou lógica para a autoria em tela.

No mesmo sentido, para que os cidadãos sejam capazes de se reunir (formal ou informalmente), estabelecer trocas argumentativas e produzir decisões publicamente válidas e legítimas, deve-se assegurar a existência de fóruns, direitos políticos e espaços (formais e informais) abertos à participação política - ao exercício do civismo - por sua parte. $\mathrm{O}$ processo de produção normativa pressuposto no procedimentalismo da autolegislação, destarte, não se limita, mas se ancora e se viabiliza, no medium do direito, definidor das liberdades privadas e das condições em que se dá a deliberação (cf. Habermas, 2002a, pp. 285-97 e pp. 326-37).

Esse esquema parece logicamente irrepreensível e explicaria de maneira suficientemente clara a relação entre direito e política no procedimentalismo não agregacionista da política deliberativa habermasiana. Mas, como exposto, o autor não é um naturalista. A justificação do direito constitucional, portanto, não tem outra saída, no pensamento pragmatista em pauta, senão fincar-se, igualmente, no solo discursivo-procedimental.

O medium do direito estabelece as condições de possibilidade e delimita os termos válidos para o exercício das 
práticas democráticas e, a um só tempo, se legitima e se constitui nos termos desse exercício. Em um sofisticado argumento e desenho institucional, Habermas explica as peculiaridades procedimentais e discursivas próprias aos fóruns políticos e à jurisdição constitucional, apontando para o modo como ambos se respaldam em procedimentos, mas como, igualmente, produzem certa rigidez, a limitarem-se, qual substâncias ou conteúdos uns em relação aos outros, mutuamente.

O direito seria como um "idioma", ou seja, o meio a partir do qual as decisões públicas têm lugar. Assim, condicionaria, limitaria e restringiria o rol de possibilidades dessas decisões, mas o faria enquanto seu possibilitador, sua indispensável ferramenta. O próprio direito, assim como a gramática, que permite a comunicação, mas é gestada em sua prática, seria fruto de processos decisórios empreendidos pelos cidadãos no exercício de sua autonomia pública. 240 Conclui-se, então, que o monismo jurídico estatal, a definição de direitos constitucionais fundamentais e a jurisdição constitucional são indispensáveis ao procedimentalismo democrático habermasiano. Se é um dado que em Habermas não há um procedimentalismo estritamente político, ou agregativo, também é certo que nenhum lastro último, substantivo, comparece para constituir o Estado, dispor sobre o direito ou delimitar o conteúdo da deliberação.

Uma discussão importante que segue dessa síntese pragmática entre o substancialismo dos direitos fundamentais e o procedimentalismo agregacionista é se, realmente, logra-se, nessa formulação, uma superação quanto às históricas clivagens que o debate sugere (soberania popular x direitos humanos, indivíduo x sociedade, processo parlamentar $\mathrm{x}$ jurisdição constitucional etc.), ou se, lado outro, incorre-se em um sistema meramente circular em que a política democrática constitui o direito, que delimita os termos de exer- 
cício da democracia, que, por sua vez, volta a engendrar o direito, e assim sucessivamente ${ }^{9}$.

Essa circularidade, por si só um problema filosófico-político que não pode ser desprezado, ganha uma aparente solução, em Habermas, que pode pôr a perder todo o potencial crítico ou radical-democrático de sua teoria política. Ocorre que, depois de muito discutir as oscilações do Estado liberal em direção ao Estado social até o seu modelo procedimentalista do direito, além de tecer considerações sobre hermenêutica constitucional, Habermas (2003, v. I, p. 326) assevera que "o tribunal constitucional deve proteger o sistema de direitos que possibilita a autonomia privada e pública dos cidadãos". Indo além, afirma que o controle sobre os "pressupostos comunicativos e condições procedimentais do processo de legislação democrático" (Habermas, v. I, 2003, p. 326), ou seja, sobre as condições da deliberação pública, é entregue àquelas que são, em geral, as mais oligárquicas, patriarcais e herméticas das instituições do Estado, nomeadamente as Cortes constitucionais.

Ou seja, a informalidade da esfera pública do mundo da vida refreia a burocracia e impede a mercantilização de todas as relações humanas, mas o faz segundo o idioma do direito. Este, por sua vez, põe as condições e os limites da deliberação pública, mas nos estritos termos em que é interpretado pelas Cortes constitucionais. Há, portanto, um papel central reservado ao Estado na democracia deliberativa habermasiana. Esse papel reside, de saída, no reconhecimento de que os sistemas sociais guiados por códigos (dinheiro ou poder) são inevitáveis nas sociedades em que

\footnotetext{
9 O autor chega a reconhecer essa circularidade: "Na base da legitimação do Estado constitucional há, certamente, uma relação circular entre democracia e direitos humanos. Não obstante, à medida que argumentos metafísicos e religiosos já não contam em público, os direitos humanos não podem - em nome do "direito natural" - reclamar validade independentemente de alguma autorização democrática" (Habermas, 2005, p. 386; tradução do autor).
} 
o mundo da vida se racionaliza e em que há uma intensa diferenciação social (Habermas, 2012). Ainda além, o aparato legislativo e, especialmente, judiciário, são fundamentais para a compreensão habermasiana da política democrática. O procedimentalismo democrático de Habermas está, com efeito, contido pela norma jurídico-constitucional em sua dimensão estática e submetido aos vetos e injunções da jurisdição constitucional nas suas vicissitudes.

As ideias anteriormente sintetizadas não esgotam o tratamento conferido pela primeira geração do deliberacionismo ao tema do papel do Estado. Joshua Cohen possui uma leitura alternativa, cujo cerne reside em uma nova definição da relação entre procedimento e substância.

\section{A democracia deliberativa do bem comum: o procedimentalismo mitigado de Joshua Cohen}

Ao apurar a relação entre procedimento e substância na

242 democracia deliberativa, Joshua Cohen parte de uma premissa compatível com a linha de raciocínio procedimentalista. Afirma que "a legitimidade emerge das discussões e decisões dos membros da sociedade, quando formuladas e expressadas por meio de instituições sociais e políticas designadas a reconhecer sua autoridade coletiva" (Cohen, 2007, p. 115). O problema que o autor decide abordar a partir desse enunciado reside na já recorrente questão enfrentada pela filosofia política em sociedades complexas, desencantadas e despojadas dos fundamentos últimos metafísicos ou naturalistas: quem é a coletividade onde reside a autoridade em questão?

Se, por exemplo, a coletividade é definida pela pertença a uma religião, então a "autoridade coletiva" se desdobra da conformidade entre as decisões e algum eventual livro sagrado, dogma, mandamento ou prática associada àquele credo. Se, por outro lado, entende-se por coletividade alguma tradição comum, consignada no compartilhamento de 
uma narrativa histórica da conformação do sentimento de "nós", segue que aqueles que não se integram a esse sentimento (como, por exemplo, palestinos em Israel), estariam alijados do processo político-democrático e não integrariam a base de que se constitui a "autoridade coletiva".

Sob sociedades plurais e complexas, não é possível fundamentar-se o poder na etnia ou em fatores substantivos e homogeneizantes congêneres. Diante dessa constatação, Cohen se pergunta se a única maneira de pensar a política nesse cenário seria o procedimentalismo extremo, de natureza agregativa. $\mathrm{O}$ autor responde negativamente a essa pergunta e, assim, formula as bases de uma democracia deliberativa em que substância e procedimento se combinam no afã de se adequarem ao "fato do pluralismo razoável”, definido pelo autor como "o fato de que há concepções de valor distintas, incompatíveis, cada uma razoável, segundo as quais as pessoas se sentem sob condições favoráveis para o exercício de sua razão prática" (Cohen, 2007, p. 117).

Em síntese, diante do argumento de que o fato do pluralismo razoável parece conduzir inexoravelmente ao procedimentalismo agregativo, Joshua Cohen se propõe a apresentar uma alternativa democrática mais substancial, e ainda mais adequada, segundo o juízo do autor, ao pluralismo.

Assim como Habermas, Cohen também se depara com a necessidade de harmonizar autonomia pública e autonomia privada, identificadas, no glossário do autor, sob os nomes, respectivamente, de liberdade dos antigos e liberdade dos modernos. O teórico político estadunidense concorda, em linhas gerais, com a tese da mútua pressuposição adotada por Habermas, mas apresenta duas fundamentais objeções à maneira - formalista - como o frankfurtiano chega ao seu entendimento.

Primeiramente, Cohen não concorda com a maneira como Habermas, na obra Direito e democracia..., concede à 
forma jurídica tanta força para o argumento democrático-deliberativista. Adicionalmente, não identifica no princípio do discurso habermasiano um meio adequado para fins de garantia das liberdades básicas ou fundamentais. Para Cohen, o princípio $d$, ao dar conta de razões em sentido genérico, antes de razões especificamente políticas intercambiadas em uma comunidade composta por membros iguais, não se vincula aos direitos fundamentais de ordem não política da maneira como pretende Habermas. De outro modo, parece se oferecer aos riscos de um procedimentalismo sem contenções, correlato, nesse aspecto, ao agregacionismo. Se elementos éticos, morais, ou religiosos podem contar como razões no processo discursivo aludido pelo princípio do discurso, então, para Cohen (1999, p. 395), "qualquer coisa pode sobrevir do discurso", de modo que não haveria limites impostos pela própria deliberação, como Habermas pretende. As liberdades não políticas, 244 portanto, não estariam vinculadas ao resultado de processos discursivos da maneira como Habermas sugere (cf. Cohen, 1999).

Como alternativa aos dois problemas mencionados, Cohen formula uma alternativa de democracia deliberativa reconhecidamente associada a elementos substanciais, os quais seriam não apenas compatíveis, como garantidores do fato do pluralismo razoável.

O primeiro princípio propugnado pelo autor é o da inclusão deliberativa. Por meio desse princípio, assegura-se que, mais do que uma mera inclusão igualitária dos interesses de todos os cidadãos, a democracia exige que se encontrem "razões aceitáveis politicamente - razões que são aceitáveis para os outros - dado o pano de fundo de diferenças de convicções prudentes" (Cohen, 2007, p. 126). Isso significa que o processo deliberativo não pode, coerentemente, suprimir o exercício de liberdades, como a de crença religiosa, que implicariam a descarac- 
terização de participantes. Se assim ocorresse, as pessoas seriam afastadas da própria deliberação e veriam negadas a própria condição de igualdade. Assim, direitos não diretamente políticos - como a livre expressão de credos - se vinculam à deliberação pública, uma vez que o seu reconhecimento assegura a condição de iguais entre os que professam diferentes - e incompatíveis entre si - concepções fundamentais e inegociáveis - como a religião - sobre o mundo e a boa vida (cf. Cohen, 2007). Vê-se, pois, um primeiro caso de garantia substancial que não depende de argumentos metafísicos ou jusnaturalistas - inexoravelmente etnocêntricos -, mas que, de modo diametralmente oposto, se coaduna com o pluralismo e até mesmo o assegura.

O segundo princípio formulado por Cohen para a democracia deliberativa diz respeito ao bem comum. De acordo com esse princípio, nem todas as razões seriam válidas no processo discursivo. Para Cohen, em clara demonstração da influência de uma noção rawlsiana de justiça sobre o respectivo pensamento, se a democracia é um corolário político da igualdade, então se conclui que as decisões proferidas democraticamente não podem produzir situações de iniquidade, em que uns se beneficiam indevidamente em prejuízo dos outros, independentemente das razões sustentadas para tanto.

Finalmente, Cohen procura conectar a democracia deliberativa às chamadas "liberdades dos antigos", ou direitos de participação política, o que é efetivado pela proposição de um "princípio de participação". Segundo esse princípio, não são válidas restrições, ainda que fundamentadas em critérios como expertise ou fluidez da deliberação, que afastem qualquer cidadão do pleno direito de participar, em igualdade formal e substantiva de condições, das decisões políticas. Assim, reservas quanto ao acesso a cargos públicos, à votação e a quaisquer mecanismos que permitam o 
exercício de "influência efetiva" são reprochadas por esse terceiro princípio de natureza substancial, que assegura o pluralismo e se coaduna com a lógica discursiva da deliberação (cf. Cohen, 2007).

O debate acerca da relação entre substância e procedimento na democracia deliberativa, tal como aqui equacionado a partir das distinções entre as formulações de Jürgen Habermas e Joshua Cohen, indica que, seja no formalismo jurídico do autor alemão, seja no substancialismo lastreado na igualdade e no fato do pluralismo razoável de Cohen, a deliberação pública não compreende apenas a esfera do livre debate, prescindindo das condições para que tal ocorra e de suas consequências.

Dessa constatação, segue que o Estado, como titular da jurisdição constitucional e do processo legislativo (Habermas) ou como garantidor de condições substantivas de igualdade de acesso à participação política (Cohen), não 246 parece apenas receber impulsos da deliberação pública, como uma leitura imediata da teoria do agir comunicativo, sem contextualização na obra posterior de Habermas, poderia sugerir. De fato, o Estado retroalimenta a esfera pública mediante limites, constrangimentos e práticas positivas, destinadas a possibilitar as trocas argumentativas entre cidadãos orientados pela força dos melhores argumentos, e a reconhecer, senão a legitimidade, ao menos a validade dos resultados de tais trocas.

Na esteira do veio temático aberto pelo debate tratado nesta seção, encontra-se a controvérsia diretamente concentrada sobre o papel que o Estado deve cumprir no próprio contexto deliberativo, se de aparato poroso a ser influenciado pelos fluxos comunicacionais advindos da esfera pública segundo o idioma do direito, como no modelo dual habermasiano, ou se de fomentador e promotor de espaços deliberativos no âmbito da própria burocracia. Este é o assunto perquirido a seguir. 


\section{Onde se delibera? Entre o Estado poroso à esfera pública e os espaços participativos de gênese estatal}

As diferenças entre Habermas e Cohen quanto à relação entre procedimento e substância na democracia deliberativa conformam o solo teórico em que vicejam concepções díspares acerca do papel cabível à burocracia estatal no contexto da deliberação pública.

Como visto, a filosofia de Jürgen Habermas se ancora em uma concepção dual de sociedade, segundo a clivagem nunca suficientemente esclarecida se de ordem analítica ou ontológica - entre sistemas sociais (conceito herdado, com alterações, da teoria social parsoniana) e o mundo da vida.

Em Habermas, como aqui já se apresentou, a deliberação ocorre a partir de condições de autonomia forjadas segundo o medium do direito que, na modernidade, é legítima e monisticamente posto pelo Estado, que o implementa na forma de políticas públicas, o define no espaço parlamentar e o concretiza mediante a prestação jurisdicional, com destaque, neste último caso, para as ações em que, concentrada ou difusamente, espera-se o exercício da jurisdição constitucional.

Lado outro, como sugere o modelo dual, baseado na influência dos fluxos comunicativos oriundos da esfera pública sobre a burocracia estatal, na forma aqui já enunciada, não cabe ao Estado, para Habermas, promover administrativamente as práticas de deliberação que devem ter lugar na esfera pública. Recobra-se que, na teoria do agir comunicativo, a colonização do mundo da vida pela lógica dos sistemas sociais é o risco maior para a emancipação social e o principal efeito adverso a ser contido no capitalismo tardio.

Desse modo, trazer as informais trocas argumentativas ocorrentes em espaços não burocratizados próprios da sociedade civil para o campo sistêmico, conduzido pelo meio do poder, atinente ao Estado, significaria um potencial sequestro da energia, da vitalidade e da potencialidade 
racional-comunicativa ali ocorrente, para um cenário que reduziria todo esse potencial emancipatório à sua lógica, sensível apenas a mensagens expressadas segundo o código do poder. Mesmo após a sua "virada legalista"10, manifestada em Direito e democracia..., os estudos políticos de Habermas se mantêm céticos quanto à possibilidade de que a burocracia implemente e orquestre, em seu próprio âmbito, as práticas deliberativas. Confira-se, a respeito, essa elucidativa passagem de um artigo em que o autor sumariza seu argumento:

Justamente os processos comunicativos que passam pelo filtro deliberativo dependem de recursos do universo vital da cultura política libertadora, de uma socialização política esclarecida e sobretudo das iniciativas de associações formadoras de opinião -, recursos que se formam de maneira espontânea ou que, em todo caso, só podem ser atingidos com grande dificuldade, caso o caminho escolhido para se tentar alcançá-los seja o do direcionamento político (Habermas, 2002a, p. 284).

Habermas deposita demasiada confiança na categoria sociedade civil e nos movimentos sociais, de modo que parece pretender preservar seu caráter virtuoso da incursão sistêmica perpetrada pelo Estado. A democracia deliberativa preconizada pelo autor, portanto, exige do aparato estatal uma porosidade aos discursos produzidos na esfera pública, assim como um sistema de justiça apto a garantir a autonomia privada dos agentes.

Uma crítica que se pode tecer em relação a isso repousa sobre a inexistência de efetivas diferenças, no campo da realidade social, entre o liberalismo político (no qual

\footnotetext{
${ }^{10}$ A ideia de uma "virada legalista" é recorrente em menções críticas à obra Direito e democracia... Um artigo amplamente debatido em que essa expressão aparece de modo explícito encontra-se em Love (2002).
} 
a imprensa é livre, os movimentos sociais se organizam de modo a influenciarem a opinião pública, o Parlamento reverbera - mais ou menos, a depender dos arranjos eleitorais e institucionais - a multiplicidade de opiniões e discursos ocorrentes em sociedade etc.) e o modelo normativo da democracia deliberativa em sua variante habermasiana. Sob o ponto de vista da práxis política efetivamente conduzida por cidadãos nas sociedades complexas do capitalismo tardio, Habermas parece formular justificativas mais elaboradas para o status quo, antes de propor alguma alternativa crítica, como afirma fazer, às formas democráticas já consolidadas $^{11}$.

A trajetória da teoria política de Habermas pode ser assim condensada: de uma crítica ao liberalismo democrático, chega-se a um modelo de democracia radical ancorado no conceito de esfera pública e no modelo da ação comunicativa. Até aí, com o objetivo de se afastar a reificação e redução do ser humano a cliente do Estado, como no Estado social, propõe-se uma democracia em que o centro gerador de legitimidade da política está na informalidade da sociedade, onde trocas linguísticas movidas apenas pela força não coercitiva do melhor argumento têm vez. Acontece que, para adentrarem a esfera político-legislativa, ou mesmo para encontrarem condições de ocorrência, referidas trocas devem ser codificadas segundo a linguagem do

\footnotetext{
${ }^{11}$ Veja o modo como o historiador marxista inglês Perry Anderson (2012, pp. 154-55) apresentou essa ideia: "Se a visão de Habermas da lei e da democracia é tachada de abstração fundamental das realidades empíricas de uma ordem política em que a formação da vontade popular é, no melhor dos casos, espasmódica ou vestigial, ele pode recorrer à sua vocação contrafactual. Se é acusada de não especificar nenhuma alternativa desejável, pode recorrer ao valor daquilo que já existe: uma base sólida de comunicação que só precisa ser consumada [...] Que críticas reais da ordem social se depreendem do "padrão crítico" oferecido por essa teoria? Onde exatamente podemos encontrar a 'eficácia' das idealizações que ela discerne nas práticas existentes, e por que elas são 'inevitáveis'? Quão 'parcial' - e 'distorcida' é a inscrição das normas nas condutas observáveis? [...] Tais questões estão além do trânsito dessa teoria, que foi concebida para evitá-las. Seu efeito é apologético. Nossas sociedades são melhores do que as concebemos".
} 
direito. Esta, por sua vez, é interpretada, assegurada e aplicada em definitivo pelo exercício da jurisdição constitucional. O Estado, portanto, é central na democracia deliberativa habermasiana, em especial no que se refere à sua - não eleita e, em geral, vitalícia - magistratura. Esse arranjo não consegue, ao se atar ao direito e à jurisdição constitucional, revelar-se crítico ou mais poroso às ideias em circulação na sociedade do que o liberalismo.

Antes de uma teoria radical, normativa ou crítica, a relação entre Estado e deliberação pública encampada pelo sucessor da cadeira ocupada por Adorno pode dar vez à caracterização cunhada por Seyla Benhabib (2007, p. 75), que descreve "a democracia deliberativa como uma teoria que esclarece os princípios já implícitos e a lógica das práticas políticas existentes”.

Joshua Cohen parece notar o problema antes acusado e oferece, no artigo "Reflections on Habermas on demo250 cracy”, destaques à tese da simples influência dos cidadãos sobre o Estado, de maneira a exigir mais do que mera porosidade à opinião circulante na esfera pública. Para que a democracia radical cumpra suas promessas de assegurar uma legitimidade estribada nos exigentes requisitos da deliberação ideal, o autor percebe que, para além de uma esfera pública autônoma e da possibilidade de que os participantes tenham acesso e manifestem posições sobre problemas e valores políticos, é fundamental que haja espaços institucionalizados, regulares, em que os participantes produzam decisões políticas e, ademais, aprimorem a qualidade dos discursos que habitam a esfera pública informal (cf. Cohen, 1999, pp. 410-11).

No modelo proposto pelo autor, denominado poliarquia diretamente deliberativa, a democracia possui, adicionalmente aos predicados de autônoma e de deliberativa, o atributo de institucional. Experiências como policiamento e gestão da segurança pública discutidos em nível comunitário-local, 
escolas administradas descentralizadamente por pais e mestres e políticas de desenvolvimento local geridas em grau de colaboração com entes da sociedade civil são, com efeito, bem recebidas (Cohen, 1999, pp. 411-412). A poliarquia diretamente deliberativa não teme o Estado como irremediável potência colonizadora do mundo da vida, de modo que alicerça as pilastras do edifício teórico da democracia deliberativa com vigas de arranjos participativos institucionalmente estatuídos.

Cohen, porém, não oferta uma resposta à objeção habermasiana de que o Estado opera segundo o código do poder e nesse idioma transcreve as práticas ocorridas em seu interior. A poliarquia diretamente deliberativa apresenta uma saída consistente para o problema da mera influência - ainda que legalmente codificada - da comunicação ocorrente na esfera pública sobre o aparato estatal. Incorre em problema inverso, todavia, ao não esclarecer de que modo o Estado moderno conterá espaços decisórios participativos que não reduzam a energia crítica da sociedade civil à sua lógica sistêmica, operada segundo estímulos eleitorais ou fiscais. Quem decide sobre as regras dos espaços participativos? Quem controla os procedimentos e a elegibilidade, senão aqueles que estão no volante de uma nave movida, em qualquer caso, por votos garimpados nas eleições e tributos coletados na condição de medida da acumulação capitalista? (cf. Offe, 1984).

Joshua Cohen procura repor o ponto de chegada de Habermas, referente aos problemas da deliberação no seio do aparato burocrático. Essa empreitada teórica fica a dever, entretanto, uma reposição do ponto de partida segundo o qual o Estado, na atual fase da modernidade capitalista, não pode simplesmente optar por funcionar ou não em conformidade com os seus predicados sistêmicos, próprios ao modelo teleológico da ação. Por um lado, Cohen (1989; Cohen e Fung, 2004) concorda com uma democra- 
cia referenciada no modelo comunicativo da ação e refere-se expressamente à obra de Habermas quando explica o processo argumentativo pressuposto na deliberação. Por outro, não explica de que modo o agir comunicativo invadirá as hostes burocráticas e engendrará a práxis esperada na poliarquia diretamente deliberativa.

Entre a influência da esfera pública, juridicamente codificada, sobre o sistema estatal, de um lado, e a possibilidade de espaços estatais abertos à deliberação, de outro, não fica claro como procedimento e substância se relacionam nas diferentes variantes de um modelo democrático que se propõe, em qualquer caso, a legitimar decisões segundo a força dos melhores argumentos.

Habermas e Cohen ostentam divergentes compreensões 252 acerca da relação entre o aparato estatal e a deliberação pública. Ambos, todavia, não enfrentam fundamentais indagações que ressaem dos respectivos escritos. Como deve ser a democracia deliberativa? Com o que se parece? A inconclusiva e problemática relação entre Estado e deliberação pública se revela como um indicador de problemas mais profundos nessa, hoje tão influente, corrente da teoria política contemporânea.

O problema da democracia deliberativa, mais visível em sua relação com o Estado, pode, a partir do que aqui se desenvolveu, ser compreendido pela seguinte decomposição analítica:

1. A democracia deliberativa pretende restabelecer, por meio de um sistema jurídico formal, garantido por magistrados e pelo exercício da jurisdição constitucional lastreada na norma positiva, as condições de possibilidade de uma deliberação que operaria como mimese, ampliada à universalidade de participantes, da decaída 
esfera pública europeia, branca, masculina e burguesa oitocentista. As ideias, nesta restabelecida esfera pública, devem estar validadas concomitantemente na sinceridade do agente, na correção objetiva e na adequação normativa. Não se explica, portanto, como esta última possa dar conta, sozinha, da missão de ser medium e elemento legitimador de práticas comunicativas que vão muito além dos seus limites.

2. Habermas elabora um modelo de democracia que pretende atar a legitimidade das decisões públicas à força dos melhores argumentos, gestados na informalidade da esfera pública do mundo da vida. Ocorre que, segundo o próprio autor, o processo de racionalização do mundo da vida (ou seja, de gestação dos supracitados argumentos) leva à inexorável constituição de subsistemas conduzidos por meios, dentre os quais está precisamente o Estado, colonizador e destruidor da livre troca comunicativa no mundo da vida. Ressai, assim, um nítido curto-circuito teórico.

3. Finalmente, Cohen, tentando restabelecer a democracia deliberativa e dar-lhe uma conotação tangível, concede ao Estado a possibilidade de estruturar e manter espaços próprios à deliberação pública. Nesse caso, todavia, o que se identifica é uma teoria alicerçada no conceito habermasiano de deliberação, que pretende lhe amputar, contudo, a constitutiva noção de separação entre os sistemas, no seio dos quais ocorre o agir racional-com-respeito-a-fins, e o mundo da vida, palco da ação comunicativa. Se o aparato estatal pode ser âmbito da livre argumentação, então inexiste o problema (colonização do mundo da vida) para o qual a democracia deliberativa pretende ser uma solução. A saída de Cohen acaba por girar em falso, porquanto lhe falta uma teoria do Estado que lastreie a sua versão alternativa da teoria da democracia habermasiana. 
Sob signo do deliberacionismo, pode-se pensar uma comunidade real em que as pessoas são livres para a crítica e o debate, mas a última palavra sobre as próprias condições da crítica e a linguagem em que se transmite o debate estão nas mãos de uma oligarquia composta pela magistratura, responsável pela jurisdição constitucional. É possível, de outro modo, pretender-se uma república repleta de espaços participativos, organizados e estimulados pelos agentes estatais eleitos e seus subordinados técnicos, onde as pessoas intercambiam argumentos e legitimam as decisões com base nas melhores razões. É igualmente verossímil a imagem de uma democracia não muito diferente dos marcos liberais, em que a sociedade influencia, por mecanismos de opinião e crítica informais, o modo como atua o Estado.

$\mathrm{O}$ contraste ajuda a esclarecer o argumento aqui apresentado. Leninistas - que, afinal, querem acabar com o Estado - debruçaram-se, por decênios a fio, sobre os contornos 254 efetivamente devidos ao momento transitório que definem como ditadura do proletariado. Downs e os cientistas políticos que o acompanham recitam com clareza e precisão o papel do Estado, da legalidade e dos direitos na teoria econômica da democracia. Da mesma sorte, o pluralismo de Dahl não encerra maiores ambiguidades quanto ao que se deve esperar para que se alcance os maiores valores de $x$ e $y$ no plano cartesiano composto por contestação pública e direitos de participação. O mesmo não se pode dizer da democracia deliberativa. Os traços da teoria política inspirada na filosofia habermasiana se revelam não apenas contraditórios entre os seus diferentes adeptos, como muito palidamente delineados em todas as suas formulações, desde as origens até a chamada virada empírica.

$\mathrm{O}$ que se pretendeu argumentar aqui é que essas omissões e potenciais contradições não são um acaso ou problema pontual no deliberacionismo democrático. São, na verdade, a expressão concreta, no plano da teoria demo- 
crática, de uma filosofia para a qual o Estado encerra uma conquista evolutiva à bem-vinda racionalização do mundo da vida, mas, ao mesmo tempo, retribui à sua gênese com pressões colonizadoras e mediatizadoras.

O mundo da vida racionalizado possibilita o surgimento e o crescimento de certos subsistemas, cujos imperativos, ao se tornarem autônomos, ricocheteiam de modo destrutivo sobre o próprio mundo da vida (Habermas, 2012, p. 336).

Não há apenas uma limitação teórica periférica, situada sobre o detalhamento do Estado na democracia deliberativa. Essa questão é um proxy de dificuldade muito mais profunda. A teoria da democracia deliberativa está atada a um marco filosófico que jamais explicou devidamente de que modo o mundo da vida e o agir comunicativo podem, a um só tempo, gerar o sistema do Estado como fruto de sua racionalização, sucumbirem à colonização sistêmica que eles mesmos semearam e, ademais, servirem como o único e eficaz remédio para conterem precisamente essa colonização.

A partir dessas três possibilidades, todas originárias da teoria do agir comunicativo, surgiram múltiplas e mutuamente incompatíveis proposições no plano mais concreto da teoria política. De uma radicalização democrática associada a inovadores arranjos participativos, como em Cohen, à descrição por outros meios da realidade nua do Estado liberal, como na constatação de Benhabib, a democracia deliberativa pode se encaixar em quase tudo, o que a mantém em uma pouco confortável posição, se o escopo for a inovação teórica voltada ao diagnóstico ou à solução de problemas e desafios concretos.

\section{Francisco Mata Machado Tavares}

é professor adjunto da Faculdade de Ciências Sociais e coordenador da pós-graduação em Ciência Política na Universidade Federal de Goiás (UFG). 


\section{BIBLIOGRAFIA}

ANDERSON, P. 2012. Espectro: da direita à esquerda no mundo das ideias.

Trad. Fabrizio Rigout e Paulo Cesar Castanheira. São Paulo: Boitempo. BÄCHTIGER, A. et al. 2009. "Disentangling diversity in deliberative democracy: competing theories, their blind spots and complementarities". The Journal of Political Philosophy, Oxford [compilation].

BENHABIB, S. 2007. "Sobre um modelo deliberativo de legitimidade democrática”. In: WERLE, D.; MELO, R. S. (orgs. e trads.). Democracia deliberativa. São Paulo: Esfera Pública.

BOHMAN, J. 1998. "The coming of age of deliberative democracy". Journal of Political Philosophy, v. 6, n. 4, pp. 400-25.

BURKE, P. 2002. "A esfera pública 40 anos depois". Trad. Victor Aiello Tsu. Folha de S.Paulo, Caderno Mais!, São Paulo, 24 mar.

CALHOUN, C. (ed.) 1992. Habermas and the public sphere. Cambridge: MIT Press. COHEN, J. 1989. "Deliberation and democratic legitimacy". In: HAMLIN, A.; PETTIT, P. The good polity. Oxford: Blackwell.

1999. "Reflections on Habermas on democracy". Ratio Juris, v. 12, n. 4. . 2007. "Procedimento e substância na democracia deliberativa". In: WERLE, D.; MELO, R. S. (orgs. e trads.). Democracia deliberativa. São Paulo: Esfera Pública.

COHEN, J.; FUNG, A. 2004. "Radical democracy". Swiss Political Science Review, v. 10, n. 4, pp. 23-34.

DRYZEK, J. S. 2004. "Legitimidade e economia na democracia deliberativa”. In: COELHO, V. S. P.; NOBRE, M. (orgs.). Participação e deliberação: teoria democrática e experiências institucionais no Brasil contemporâneo. São Paulo: Ed. 34. 1997. Direito e democracia: entre facticidade e validade. Trad. Flávio Beno Siebeneichler. v. II. Rio de Janeiro: Tempo Brasileiro.

GURZA LAVALLE, A. 1997. "A humildade do universal: Habermas no espelho de Rawls”. Lua Nova, n. 40/41, pp. 146-218.

HABERMAS, J. 1997. Direito e democracia: entre facticidade e validade.

Trad. Flávio Siebeneichler. v. II. Rio de Janeiro: Tempo Brasileiro. . 1980. "O conceito de poder de Hannah Arendt". In: FREITAG, B.;

ROUANET, S. P. Habermas: Sociologia. São Paulo: Ática. . 2002a. A inclusão do outro: estudos de teoria política. Trad. George Sperber. São Paulo: Loyola. . 2002b. Racionalidade e comunicação. Trad. Paulo Rodrigues. Lisboa: Edições 70, 2003. Direito e democracia: entre facticidade e validade. Trad. Flávio Siebeneichler. 2 ed. v. I. Rio de Janeiro: Tempo Brasileiro. 
2005. "Concluding comments on empirical approaches to deliberative politics". Acta Politica, n. 40, pp. 384-92.

2012. Teoria do agir comunicativo. v. 1. Racionalidade da ação e racionalização social. Trad. Paulo Astor Soethe. São Paulo: Martins Fontes.

HONNETH, A. 2001. "Democracia como cooperação reflexiva. John Dewey e a teoria democrática hoje". In: SOUZA, J. (org.). Democracia hoje: novos desafios para a teoria democrática contemporânea. Brasília: EdUnB.

LOVE, N. 2002. "Disembodying democracy: gendered discourse in Habermas's legalistic turn”. In: MCORMICK, J. P. (ed.). Confronting mass democracy and industrial technology: political and social theory from Nietzsche to Habermas. Durham: Duke University Press.

LUBENOW, J. A. 2010. "Esfera pública e democracia deliberativa em Habermas: modelo teórico e discursos críticos”. Kriterion, Belo Horizonte, n. 121, pp. 227-58.

MARX, K. 2005. A crítica da filosofia do direito de Hegel. Trad. Rubens Enderle e Leonardo de Deus. São Paulo: Boitempo.

MANSBRIDGE, J. et al. 2009. "The place of self-interest and the role of power in deliberative democracy". The Journal of Political Philosophy, Oxford [compilation].

MOUFFE, C. 2000. Deliberative democracy or agonistic pluralism. Vienna: Institute for Advanced Studies. (Political Science Series).

NEGT, O.; KLUGE, A. 1993. Public sphere and experience: toward an analysis of bourgeois and proletarian public sphere. Minneapolis: University of Minnesota Press.

OFFE, C. 1984. Problemas estruturais do Estado capitalista. Trad. Barbara Freitag. Rio de Janeiro: Tempo Brasileiro.

ROUSSEAU, J.-J. 2002. Do contrato social. Trad. Rolando R. da Silva. Disponível em: <http://www.dominiopublico.gov.br/download/texto/ cv00014a.pdf>. Acesso em: 28 nov. 2012.

RUSTOW, D. A. 1999. "Transitions to democracy: toward a dynamic model”. In: ANDERSON, Lisa. Transitions to democracy. New York: Columbia University Press.

SANTOS, B. de S.; AVRITZER, L. 2002. "Introdução: para ampliar o cânone democrático”. In: SANTOS, B. de S. (org.). Democratizar a democracia: os caminhos da democracia participativa. Rio de Janeiro: Civilização Brasileira.

STEENBERGEN, M. et al. 2003. "Measuring political deliberation: a discourse quality deliberation: a discourse quality index". Comparative European Politics, n. 1. 


\section{O ESTADO NA DEMOCRACIA DELIBERATIVA: AS RAÍZES DE UMA ANTINOMIA}

\section{FRANCISCO MATA MACHADO TAVARES}

Resumo: $\mathrm{O}$ artigo pretende identificar na Teoria do Agir Comunicativo a explicação para o tratamento ambíguo conferido ao Estado pelas diferentes variantes da teoria da democracia deliberativa. A partir de uma crítica teórica, constata-se que o deliberacionismo se refere a práticas políticas não apenas distintas entre si, como antagônicas. Propõe-se que a indefinição quanto ao preciso significado da democracia deliberativa é um desdobramento dos seus fundamentos habermasianos. Descobre-se que, na filosofia de Habermas, o mundo da vida se racionaliza para criar o sistema estatal, mas, igualmente, por ele é colonizado ou destruído. Dessa antinomia segue uma teoria política para a qual o Estado pode ser tanto um espaço de simples influência informal dos fluxos comunicativos egressos da esfera pública, como o seu oposto, na condição de um aparato promotor de fóruns decisórios participativos.

Palavras-chave: Democracia Deliberativa; Teoria do Agir Comunicativo; Jürgen Habermas; Joshua Cohen.

\section{THE STATE IN DELIBERATIVE DEMOCRACY: THE ROOTS OF AN ANTINOMY}

Abstract: The paper aims at identifying, back in the Theory of Communicative Action, an explanation for the ambiguous accounts of the State detected along the different versions of the theory of deliberative democracy. By the means of a theoretical critique, it is realized that deliberationism implies political practices not only distinct but reciprocally antagonistic. It is proposed that the indefinition over the precise meaning of deliberative democracy is a consequence of this theory's Habermasian grounds. In the philosophy 
of Habermas, the lifeworld is rationalized to create the state, but is also colonized or destroyed by this system. This antinomy implies a political theory to which the state may be both a space for mere informal influence reasons that come from the public sphere as its opposite, as an apparatus aimed to establish participatory forums.

Keywords: Deliberative Democracy; Theory of Communicative Action; Jürgen Habermas; Joshua Cohen.

Recebido: 17/10/2013 Aprovado: 03/07/2015 